NASA Technical Memorandum 100285

AIAA-88-0826

\title{
The Bit-Error Rate Performance of a Satellite Microwave Matrix Switch
}

Robert J. Kerczewski

Lewis Research Center

Cleveland, Ohio
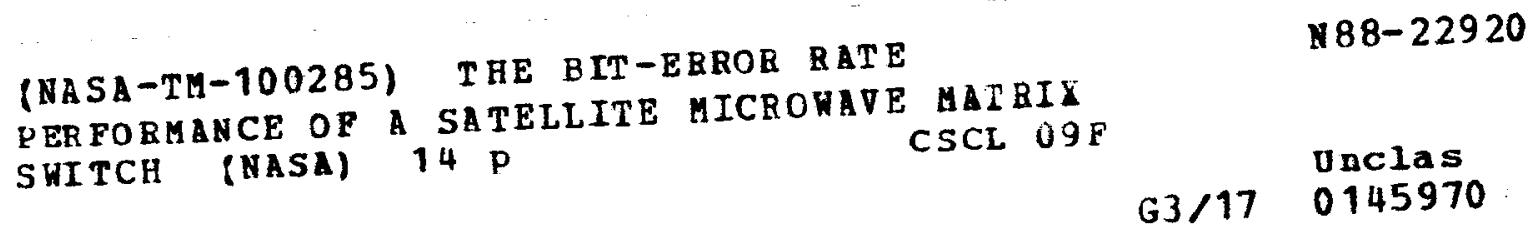

N $88-22920$

Unclas

G3/17 0145970

Prepared for the

12th International Communication Satellite Systems Conference sponsored by the American Institute of Aeronautics and Astronautics Arlington, Virginia, March 13-17, 1988 
THE BIT-ERROR RATE PERFORMANCE OF A SATELLITE MICROWAVE MATRIX SWITCH

\author{
Robert J. Kerczewski \\ National Aeronautics and Space Administration \\ Lewis Research Center \\ Cleveland, Ohio 44135
}

\section{Abstract}

The matrix switch is a critical element of communications satellites employing multiple beam antennas and on-board switching. Two proof-ofconcept models of a microwave matrix switch have been developed under NASA-sponsored contracts. These switches have undergone extensive testing at NASA Lewis Research Center to determine their operating characteristics in a system environment. The results of these tests indicate the effect of the matrix switch on the overall system operation.

\section{Introduction}

Communications satellite designs are beginning to employ multiple beam antennas and on-board switching to increase the efficiency and reduce the cost of communications systems. A critical element of such a system is the satellite matrix switch. These switches are required to provide fast switching speeds and adequate isolation between crosspoints while contributing very little degradation to the signals being transmitted through the system.

NASA Lewis sponsored the development of two proof-of-concept ( $P O C$ ) satellite microwave matrix switches, one built by General Electric Company (GE), Valley Forge, $P A$, and the other by ford Aerospace and Communications Corporation. Palo Alto, CA. An extensive in-house testing program at NASA Lewis has established most of the operating characteristics of these switches, with the results previously reported. I Through a second series of tests at NASA Lewis, the signal degradation resulting from transmission through the matrix switches, and in particular, the performance variation of a satellite communications system as different matrix switch crosspoints are used, has been measured. This paper presents and discusses the results of those measurements.

\section{POC Matrix Switch Description}

The matrix switches were designed to have 20 inputs and 20 outputs. In order to reduce the cost of the POC models, only a portion of the available 400 crosspoints were populated with switching elements. The GE switch contained 61 active crosspoints and the ford switch contained 65 active crosspoints.

Both contractors chose a coupled crossbar architecture for the ir POC models.2,3 Figure 1 is a diagram of this architecture. The input and output transmission lines are coupled to each other through a switching element (described below). With the switch open, the input and output lines are isolated. With the switch closed, the input and output lines are connected with roughly $20 \mathrm{~dB}$ of insertion loss. The most significant differences between the design approaches of the two contractors were the values of the coupling coefficients used in the coupled crossbar design and the packaging. For the GE switch, the coefficients were chosen to be $15 \mathrm{~dB}$ for all crosspoints, while in the Ford switch the coupling coefficients were increased for crosspoints farther from the $R F$ input to minimize the insertion loss variation between crosspoints.

The different packaging approaches are seen in Figs. 2 and 3 . Figure $2(a)$ shows the distribution of crosspoints for the Ford switch. In the photograph of the ford switch (fig. $2(b)$ ) the arrangement of crosspoints in the top chassis can be seen. The GE switch crosspoint distribution ( $F i g .3(b)$ ) contains five input columns, two of which are connected to all 20 outputs. In Fig. $3(\mathrm{~b})$, several of these columns are visible. In both photographs, the digital switch control units are visible as the vertical chassis at the rear of the RF switch chassis.

Block diagrams of the switch elements are shown in Figs. $4(a)$ and $5(a)$. Both contractors used a two-stage dual-gate GaAsFET configuration with appropriate input, output, and interstage matching networks. Fast switching bipolar transistors were used to drive the GaAsFETs. Figures $4(b)$ and $5(b)$ are photographs of the ford and GE switching elements, respectively.

The greatest difficulty encountered by both contractors was impedance matching problems occurring at the input and output of the switching elements. These mismatches resulted in large amplitude ripple (versus frequency). GE's approach to this problem was to narrow the switch operating bandwidth from the design goal of $2.5 \mathrm{GHz}$ to the contract minimum of $1 \mathrm{GHz}$ in order improve the performance of the matching networks. In the ford design, the line lengths between the switching elements were varied to tune out the amplitude ripple while maintaining the $2.5 \mathrm{GHz}$ bandwidth.

\section{Matrix Switch CW Performance}

Extensive testing of both matrix switches occurred at NASA Lewis upon delivery of the POC units. Among the important parameters tested were bandwidth, insertion loss, bandpass amplitude ripple, input and output VSWR, isolation, and switching speed. These tests were conducted on all of the active crosspoints for both matrix switches, with the results summarized in Table I.

One of the critical performance parameters of a matrix switch is the isolation between input and output ports when the crosspoint is open. Poor isolation degrades the system performance by creating crosstalk interference between unconnected channels of the system. Both POC models performed well in this area, achieving isolation in excess of $50 \mathrm{~dB}$.

The switching speed as measured at NASA Lewis determined the time required for an input $R F$ signal to be switched from one output port to another. This parameter determines the maximum reconfiguration rate of the matrix switch and thus drives 
many of the TOMA operating parameters of a system employing a matrix switch. Good performance was achieved by both switches, with a 15.6-ns average speed for the ford switch and a 32.2-ns average speed for the GE switch.

The parameter which has proved to be the most important contributor to degradation of signais transmitted through a matrix switch is the frequency response. As was discussed in the previous section, impedance matching problems contributed to significant amplitude ripple for both POC models. In-band ripple for the GE switch averaged less than half that for the ford switch, at the expense of reduced bandwidth. Table I shows an average in-band ripple (as measured at NASA Lewis) of $5.60 \mathrm{~dB}$ for the Ford matrix switch and $2.23 \mathrm{~dB}$ for the GE matrix switch. Frequency response plots for typical ford and GE crosspoints are shown in Fig. 6. The general shape of the GE switch varied much less from crosspoint to crosspoint than that of the ford switch.

\section{Description of Bit-Error Rate Measurement}

A satellite communication system simulator and test bed, as shown in Fig. 7, has been developed at NASA Lewis. This simulator, consisting of hardware developed both in-house and under contract, is used to perform a variety of $\mathrm{CW}$ and modulated signal transmission tests and experiments on communication systems and system components. ${ }^{4-6}$ The system essentially simulates an end-to-end satellite communications link with two transponder channels and two ground terminals switched through an on-board matrix switch. In the series of tests described in this paper, the matrix switch is the component under test.

Using only one of the ground terminals in a loop-back mode, a modulated or unmodulated signal can be transmitted through the system. Performance of a particular component can be evaluated by transmitting signals first through the system with the component in place, and then with the component bypassed. Alternatively, the performance of two components can be compared by direct substitution into the system. With two different POC matrix switch models available for testing, both methods of evaluation can be used.

The amount of degradation introduced into the end-to-end communication system can be determined using the bypass method. In the case of the matrix switches, an equivalent amount of attenuation (about $20 \mathrm{~dB}$ ) is added in place of the switches in order to maintain consistent power levels throughout the system and thus provide a valid comparison.

In making a direct comparison of the performance of the two switches, one difference must be considered. As shown in Table I, the switches were designed to operate in two different frequency bands. The communication system simulator operates over a satellite If band of 3.7 to $6.2 \mathrm{GHz}$. This results from the IF output of the satellite low noise receiver (itself a POC development). The Ford switch, with a design frequency band of 3.5 to $6.0 \mathrm{GHz}$, very nearly matches the entire simulator system operating band. This allowed testing in three different frequency bands, one at the lower end of the band (centered at $4.25 \mathrm{GHz}$ ), one near the center of the band (centered at $5.0 \mathrm{GHz}$ ), and one at the upper end of the band (centered at $5.725 \mathrm{GHz}$ ). These three bands have been designated as bands $A, B$, and $C$, respectively. Due to the presence of other POC development components in the system, the overall frequency response even without the matrix switch is far from ideal, and the selection of these three test bands provides varying transmission characteristics against which the matrix switch test results can be viewed. in general, band $B$, near the band center of all the major system components, exhibits the best overall transmission characteristics (particularly in having the flattest frequency response), while the other two bands exhibit varying degrees of degraded transmission characteristics.

The GE switch operates over a band of approximately 6 to $7 \mathrm{GHz}$. This offers only a narrow band overlapping the upper end of the simulator system bandwidth and the lower end of the GE switch bandwidth in which testing can take place, centered at $6.025 \mathrm{GHz}$. Since the bandwidth of the GE switch varies somewhat from crosspoint to crosspoint, the 12 crosspoints with the most frequency overlap were selected for these tests. Thus, the GE test band does not coincide with any of the ford test bands.

The bit-error rate (BER) data presented in this paper was taken using an automated bit-error rate measurement system. 4 The modulated signal is produced from a serial minimum-shift-keyed (SMSK) modulator operating at $220 \mathrm{Mbps}$. This signal, encoded with a pseudo-random data sequence, is transmitted with an operating bandwidth of $330 \mathrm{MHz}$. This bandwidth (equal to 1.5 times the bit rate) represents the center lobe of the SMSK modulated frequency spectrum, and is adequate for good detection of the SMSK signal. After transmission through the system, white noise is added to the signal before being demodulated. After the signal is demodulated, the resulting received bit stream is compared to a stored replica of the original pseudo-random bit stream and the bit-error rate is calculated. The noise power is incremented in 1-dB step to provide a range of energy-per-bit to noise power density ratios $\left(E_{b} / N_{0}\right)$ at the demodulator input in order to allow an entire curve of biterror rates as a function of $E_{b} / N_{O}$ to be measured.

of significance in the performance of a satellite communication link is the operating points of the various active devices in the system, particularly the satellite high power output amplifier (HPA). For these tests, all active devices were operated linearly except the HPA (a multipower mode TWT). 7 Tests were performed with the TWT at three different operating points: saturation, I dB compression (approximately $9 \mathrm{~dB}$ input backoff from saturation), and linear (approximately $18 \mathrm{~dB}$ input backoff from saturation).

\section{Matrix Switch Bit-Error Rate Performance}

The matrix switch was tested in a static mode (no dynamic switching during BER measurement) using one system simulator ground terminal as described above. For the Ford switch, 17 crosspoints were tested with the HPA in saturation and at $1 \mathrm{~dB}$ compression and five crosspoints were tested with the HPA in the linear region. Tweive GE switch crosspoints were tested at each of the HPA operating points. 
The test data is presented in Table II. BER measurement results are summarized for the GE switch and for each of the three ford switch test bands. In addition, the results of amplitude ripple measurements are shown.

The parameter given for the BER test results is the $E_{b} / N_{0}$ required to maintain a BER of $10^{-6}$. This parameter is determined from a measured BER curve by linear interpolation between data points. For comparison, the theoretical BER curve for SMSK requires an $E_{b} / N_{0}$ of 10.51 dB at $10^{-6}$. In a back-to-back modulator-demodulator test, the degradation from the theoretical curve is $0.9 \mathrm{~dB}$.

The data in Table II clearly demonstrates the contribution to system amplitude ripple and data transmission cuality degradation of both switches. By comparing the mean values of the amplitude ripple with the measurements made with the matrix switch bypassed, the mean contribution of the matrix switches to the overall amplitude ripple of the simulator syste'n can be seen for each frequency band and HPA cperating point. The contribution of the switches to the degradation of data transmission qua'ity, as measured by the $E_{b} / N_{0}$ required to maintain a BER of $10^{-6}$ can be similarly determined.

For both switches, operation of the HPA in saturation provided a hard-limiting effect which flattened the overall frequency response. As the HPA was backed off to the $1 \mathrm{~dB}$ compression point, the amplitude ripple increased, and further backing off to the linear point allowed still a further increase. Figure 8 gives a good example of this behavior for one ford crosspoint in frequency band $C$. The BER data generally degraded as the amplitude ripple increased. Sample measured BER curves are shown in Fig. 8 for both switches showing the degradation occurring as the HPA is backed off. For the ford switch, the results for the linear HPA tests deviate somewhat from this result, possibly due to the relatively small number of crosspoints tested. Overall, operating the HPA in saturation significantly reduced the data transmission degradation attributable to the matrix switches.

In comparing the performance of the ford and GE matrix switches, several other points can be made. First, the $E_{b} / N_{O}$ required to maintain a $10^{-6}$ BER is about the same, on the average, for both switches when the HPA is saturated. The system performance deteriorates much more rapidly with the GE switch than with the Ford switch as the HPA is backed off. This is due primarily to the placement of the GE test band near the system component band edges, as described earlier. Evidence of this is the increase in amplitude ripple for the GE switch as compared to the ford switch as the HPA is backed off. The contribution to the system amplitude ripple, however, is considerably smaller for the GE switch, as would be expected considering the flatter frequency response of the GE switch.

The clearest result to be seen from the data presented is the performance variation from crosspoint to crosspoint. The standard deviation of the $E_{b} / N_{0}$ data and the amplitude ripple data shows that the GE switch, with its much flatter frequency response, significantly outperforms the Ford switch in this category. The range of highest to lowest
$E_{b} / N_{0}$ also underscores this point, and is $\$ 11$ ustrated by the sample BER plots in Fig. 10 . Even with the HPA at saturation, the range and standard deviation for the ford switch were several times higher than for the GE switch. These results indicate the relative importance of the frequency response in the design of a matrix switch.

\section{Conclusions}

In a satellite communication system employing on-board switching, a ground terminal may be required to receive transmissions through a number of the matrix switch crosspoints. Given the complex circuitry of a matrix switch, which in the future will be required to have as many as 100 inputs and outputs, it is reasonable to expect less than ideal transmission characteristics, and characteristics that vary from crosspoint to crosspoint.

The data presented indicates that although a matrix switch may meet many desirable specifications, such as switching speed and isolation, the forward transmission characteristics of the switch have a significant effect on the performance of the system in which it is employed. In particular, the frequency response in terms of amplitude ripple and variation from crosspoint to crosspoint has a measurable effect on the quality of digitally modulated signals transmitted through such a system.

The presence of a hard limiter after the switch has been shown to greatly reduce the degrading effects of the amplitude ripple of the matrix switch. Of course, a hard limiter may introduce intermodulation distortion when several frequency channels are simultaneously present. Backing off the limiter has the effect of greatly increasing the degradation caused by the matrix switch.

The ford and GE POC matrix switches demonstrate the bandwidth versus amplitude ripple tradeoff which occurs in switch design. The BER data presented shows how that tradeoff affects system performance. In particular, the BER performance varies greatiy from crosspoint to crosspoint as the amplitude ripple becomes severe. The data from the GE switch demonstrates that for switch amplitude ripple averaging $2.2 \mathrm{~d} B$, the $E_{b} / N_{0}$ required to maintain a BER of $10^{-6}$ varies about $\pm 0.6 \mathrm{~dB}$, even with no limiting present. This indicates that $2 \mathrm{~dB}$ might be a reasonable design goal for future matrix switch designs.

Since the completion of the ford and GE efforts. NASA Lewis has continued to sponsor development work on satellite matrix switches in support of numerous future NASA science projects and commercial applications, particularly in the MMIC area, which are expected to bring further improvements in matrix switch performance.

\section{References}

1. Saunders, A. "20 $\times 20$ High Speed Microwave Switches," NASA TM-83775, 1984.

2. Ho, P.T., Coban, E., and Pelose, J., "Spacecraft IF Switch Matrix for Wideband Service Applications in $30 / 20 \mathrm{GHz}$ Satellite Systems." NASA CR-168175, 1983. 
3. Cory, B.J., "Spacecraft If Switch Matrix for Wideband Service Applications in $30 / 20 \mathrm{GHz}$ Communication Satelltte Systems," NASA CR-168089, 1982.

4. Kerczewski, R.J., Daugherty, E.S., and Kramarchuk, I., "Automated Measurement of the Bit-Error Rate as a Function of Signal-to-Noise Ratio for Microwave Communications Systems," 2.9th Automatic RF Techniques Group Conference Digest, IEEE, New York, June 1987. (NASA TM-89898. )

5. Bagwell, J.W., "A System for the Simulation and Evaluation of Satellite Communication Networks," 10th Communication Satellite Systems Conference, AIAA, New York, 1984, pp. 172-180. (NASA TM-83531.)
6. Shalkhauser, K.A. and Kerczewski, R.J. "Automated Testing of Developmental Satelilite Communications Systems and Subsystems," 25 th Automatic RF Techniques Group Conference, IEEE, New York, 1985. (NASA TM-87070.)

7. Fujikawa, G. and Kerczewski, R.J., "Performance of a Ka-Band Satellite System Under Variable Transmitted Signal Power Conditions," 1987 IEEE MTT-S International Microwave Symposium and Exhibition, June 1987. (NASA TM-88984.)

TABLE 1. - SUMMARY OF CW PERFORMANCE FOR THE FORD AND GE POC MATRIX SWITCHES AS MEASURED AT NASA LEWIS RESEARCH CENTER

\begin{tabular}{|c|c|c|c|c|c|}
\hline & \multirow{2}{*}{$\begin{array}{l}\text { Contract } \\
\text { goals }\end{array}$} & \multicolumn{2}{|c|}{ Ford } & \multicolumn{2}{|c|}{ GE } \\
\hline & & Mean & $\begin{array}{l}\text { Standard } \\
\text { deviation }\end{array}$ & Mean & $\begin{array}{l}\text { Standard } \\
\text { deviation }\end{array}$ \\
\hline $\begin{array}{l}3 \text { db bandwidth }(\mathrm{GHz}) \\
\text { Insertion loss (dB) } \\
\text { Bandpass ripple, } d B \\
\text { Input VSWR } \\
\text { Output VSWR } \\
\text { Isolation, dB } \\
\text { Switching speed, ns }\end{array}$ & $\begin{array}{r}2.5(1.0 \min .) \\
15(18 \max .) \\
1.0 \\
1.2: 1(1.5 \max .) \\
1.2: 1 \\
40 \\
10\end{array}$ & $\begin{array}{r}2.7 \\
20.7 \\
5.6 \\
1.82: 1 \\
1.70: 1 \\
54.0 \\
15.6\end{array}$ & $\begin{array}{r}0.35 \\
7.62 \\
1.4 \\
0.30: 1 \\
0.26: 1 \\
5.7 \\
10.9\end{array}$ & $\begin{array}{r}1.28 \\
18.0 \\
2.23 \\
1.30: 1 \\
1.40: 1 \\
58.0 \\
32.2\end{array}$ & $\begin{array}{r}0.21 \\
4.06 \\
1.45 \\
0.09: 1 \\
0.12: 1 \\
5.7 \\
3.6\end{array}$ \\
\hline \multicolumn{2}{|c|}{$\begin{array}{l}\text { Number of active crosspoints } \\
\text { Design center frequency, GHz }\end{array}$} & \multicolumn{2}{|c|}{$\begin{array}{r}65 \\
4.75\end{array}$} & \multicolumn{2}{|c|}{$\begin{array}{r}57 \\
6.5\end{array}$} \\
\hline
\end{tabular}




\section{ORIGNAL PAGE PST \\ OF POOR QUALITY}

TABLE 2. - SUMMARY OF BER RESULTS FOR THE FORD AND GE POC MATRIX SWITCHES

a. Ford Matrix Switch

\begin{tabular}{|c|c|c|c|c|c|c|c|c|}
\hline \multirow{3}{*}{$\begin{array}{l}\text { Frequency } \\
\text { band }\end{array}$} & \multirow{3}{*}{$\begin{array}{l}\text { HPA } \\
\text { operating } \\
\text { point }\end{array}$} & \multirow{3}{*}{$\begin{array}{l}\text { Number of } \\
\text { crosspoints } \\
\text { tested }\end{array}$} & \multicolumn{4}{|c|}{$E_{b} / N_{0}$ required for $B E R=10^{-6}$} & \multirow{2}{*}{\multicolumn{2}{|c|}{$\begin{array}{l}\text { Amplitude ripple } \\
\text { for system, } \\
330 \mathrm{MHz} \mathrm{BW}\end{array}$}} \\
\hline & & & \multirow[t]{2}{*}{ Mean } & \multirow{2}{*}{$\begin{array}{l}\text { Standard } \\
\text { deviation }\end{array}$} & \multirow[t]{2}{*}{$\mathrm{High}$} & \multirow[t]{2}{*}{ Low } & & \\
\hline & & & & & & & Mean & $\begin{array}{l}\text { Standard } \\
\text { deviation }\end{array}$ \\
\hline A & $\begin{array}{c}\text { Saturation } \\
\text { Saturation } \\
1 \mathrm{~dB} \\
1 \mathrm{~dB} \\
\text { Linear } \\
\text { Linear }\end{array}$ & $\begin{array}{c}17 \\
\text { Bypassed } \\
17 \\
\text { Bypassed } \\
5 \\
\text { Bypassed }\end{array}$ & $\begin{array}{l}12.76 \\
11.41 \\
13.83 \\
11.75 \\
13.38 \\
12.13\end{array}$ & \begin{tabular}{l}
0.77 \\
\hdashline $1 .--$ \\
-1.30 \\
1.38 \\
----
\end{tabular} & $\begin{array}{l}15.19 \\
-15.95 \\
15.90 \\
-\cdots-\end{array}$ & \begin{tabular}{l}
11.89 \\
\hdashline 11.91 \\
\hdashline 12.06 \\
$-\cdots$
\end{tabular} & $\begin{array}{l}3.53 \\
1.26 \\
2.67 \\
1.70 \\
5.34 \\
2.34\end{array}$ & $\begin{array}{r}0.56 \\
---- \\
.64 \\
-.0 \\
.59 \\
-.--\end{array}$ \\
\hline B & $\begin{array}{c}\text { Saturation } \\
\text { Saturation } \\
1 d B \\
1 d B \\
\text { Linear } \\
\text { Linear }\end{array}$ & $\begin{array}{c}17 \\
\text { Bypassed } \\
17 \\
\text { Bypassed } \\
5 \\
\text { Bypassed }\end{array}$ & $\begin{array}{l}11.94 \\
11.33 \\
12.11 \\
11.20 \\
12.45 \\
11.40\end{array}$ & $\begin{array}{r}.47 \\
---- \\
.23 \\
--. \\
.22 \\
----\end{array}$ & $\begin{array}{l}13.03 \\
12.56 \\
12.78 \\
-\cdots\end{array}$ & \begin{tabular}{l}
11.43 \\
\hdashline 11.65 \\
12.24 \\
$-\cdots$
\end{tabular} & $\begin{array}{l}1.74 \\
1.30 \\
2.11 \\
1.48 \\
3.26 \\
1.72\end{array}$ & $\begin{array}{r}.36 \\
--- \\
.53 \\
-.96 \\
.9 \\
----\end{array}$ \\
\hline c & $\begin{array}{c}\text { Saturation } \\
\text { Saturation } \\
1 \mathrm{~dB} \\
1 \mathrm{~dB} \\
\text { Linear } \\
\text { Linear }\end{array}$ & $\begin{array}{c}17 \\
\text { Bypassed } \\
17 \\
\text { Bypassed } \\
5 \\
\text { Bypassed }\end{array}$ & $\begin{array}{l}12.41 \\
11.67 \\
14.31 \\
12.25 \\
12.60 \\
13.04\end{array}$ & $\begin{array}{r}.85 \\
---- \\
1.00 \\
--- \\
.97 \\
----\end{array}$ & $\begin{array}{l}15.41 \\
-17.25 \\
14.40 \\
-----\end{array}$ & $\begin{array}{l}11.78 \\
13.00 \\
11.70 \\
-----\end{array}$ & $\begin{array}{l}3.42 \\
2.02 \\
7.01 \\
4.50 \\
8.41 \\
5.32\end{array}$ & $\begin{array}{r}1.35 \\
-1.48 \\
-.80 \\
. .8\end{array}$ \\
\hline$A, B, C$ & $\begin{array}{c}\text { Saturation } \\
\text { Saturation } \\
1 \mathrm{~dB} \\
1 \mathrm{~dB} \\
\text { Linear } \\
\text { Linear }\end{array}$ & $\begin{array}{c}51 \\
\text { Bypassed } \\
51 \\
\text { Bypassed } \\
15 \\
\text { Bypassed }\end{array}$ & $\begin{array}{l}12.36 \\
11.47 \\
13.42 \\
11.73 \\
12.81 \\
12.19\end{array}$ & $\begin{array}{c}.79 \\
-1.35 \\
-1.06 \\
----\end{array}$ & $\begin{array}{l}15.41 \\
-17.25 \\
15.90 \\
----\end{array}$ & \begin{tabular}{l}
11.43 \\
\hdashline 11.65 \\
-11.70 \\
$-\cdots-$
\end{tabular} & $\begin{array}{l}2.90 \\
1.53 \\
3.93 \\
2.56 \\
5.67 \\
3.29\end{array}$ & $\begin{array}{l}1.20 \\
--- \\
2.40 \\
2.26 \\
----\end{array}$ \\
\hline
\end{tabular}

b. GE Matrix Switch

\begin{tabular}{|c|c|c|c|c|c|c|c|}
\hline \multirow{3}{*}{$\begin{array}{l}\text { HPA } \\
\text { operating } \\
\text { point }\end{array}$} & \multirow{3}{*}{$\begin{array}{l}\text { Number of } \\
\text { crosspoints } \\
\text { tested }\end{array}$} & \multicolumn{4}{|c|}{$E_{b} / N_{o}$ required for $B E R=10^{-6}$} & \multirow{2}{*}{\multicolumn{2}{|c|}{$\begin{array}{l}\text { Ampli tude ripple } \\
\text { for system, } \\
330 \mathrm{MHz} B W\end{array}$}} \\
\hline & & \multirow[t]{2}{*}{ Mean } & \multirow{2}{*}{$\begin{array}{l}\text { Standard } \\
\text { deviation }\end{array}$} & \multirow[t]{2}{*}{$\mathrm{High}$} & \multirow[t]{2}{*}{ Low } & & \\
\hline & & & & & & Mean & $\begin{array}{l}\text { Standard } \\
\text { deviation }\end{array}$ \\
\hline $\begin{array}{c}\text { Saturation } \\
\text { Saturation } \\
1 \mathrm{~dB} \\
1 \mathrm{~dB} \\
\text { Linear } \\
\text { Linear }\end{array}$ & $\begin{array}{c}12 \\
\text { Bypassed } \\
12 \\
\text { Bypassed } \\
12 \\
\text { Bypassed }\end{array}$ & $\begin{array}{l}12.33 \\
11.74 \\
14.67 \\
13.20 \\
15.25 \\
13.29\end{array}$ & $\begin{array}{r}0.10 \\
-.- \\
.33 \\
. .36 \\
. .2\end{array}$ & $\begin{array}{l}12.50 \\
-14.97 \\
-15.87 \\
----\end{array}$ & $\frac{12.13}{13.81}$ & $\begin{array}{l}2.91 \\
3.02 \\
6.32 \\
5.70 \\
7.46 \\
6.66\end{array}$ & $\begin{array}{r}0.09 \\
--.39 \\
.39 \\
-.52 \\
----\end{array}$ \\
\hline
\end{tabular}




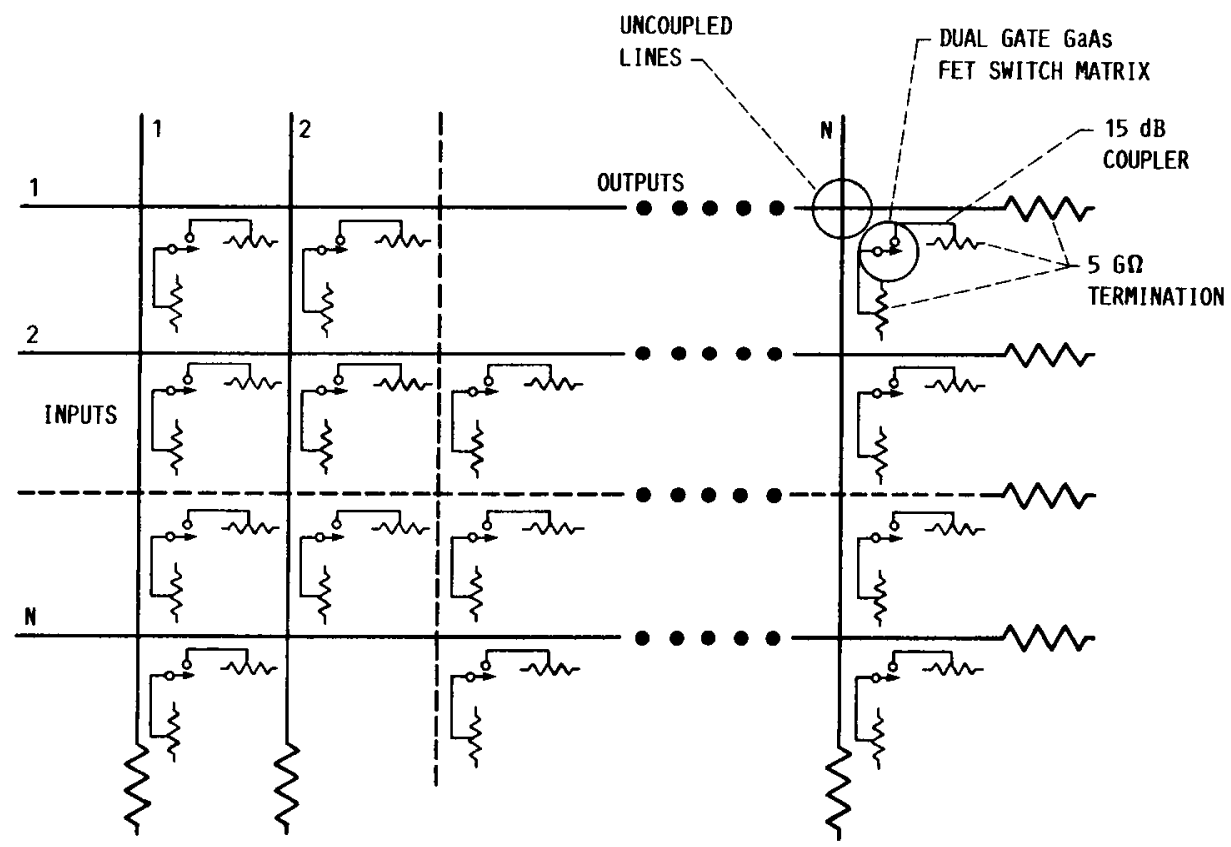

FIGURE 1.- GE COUPLED CROSSBAR ARCHITECTURE. 
OUTPUT PORTS

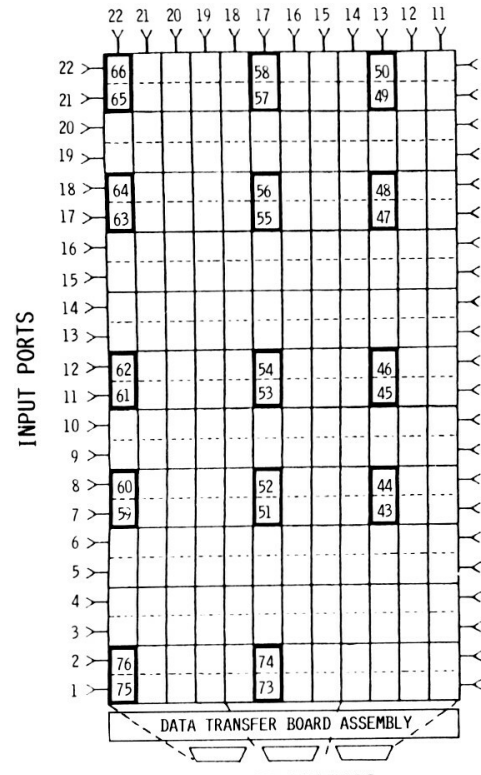

BOTTOM CHASSIS

(A) CROSSPOINT DISTRIBUTION.



(B) PHOTOGRAPH.

FIGURE 2. - FORD POC MATRIX SWITCH.

OUTPUT PORTS

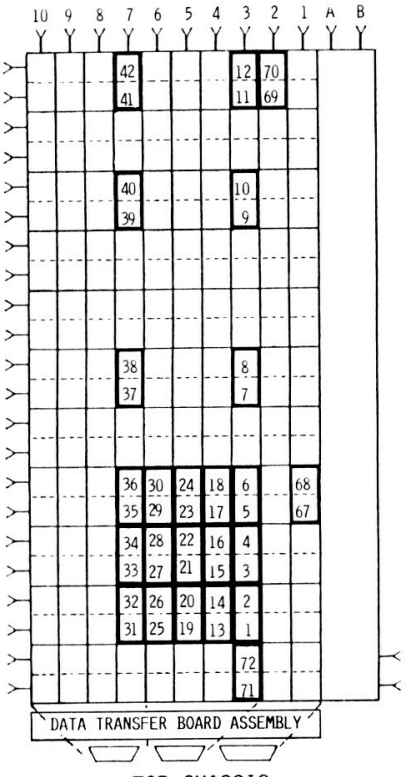

OP CHASSIS
ORIGINAI PAGE IS
OE POOR QUALITY



(i)- AROUND-OS-

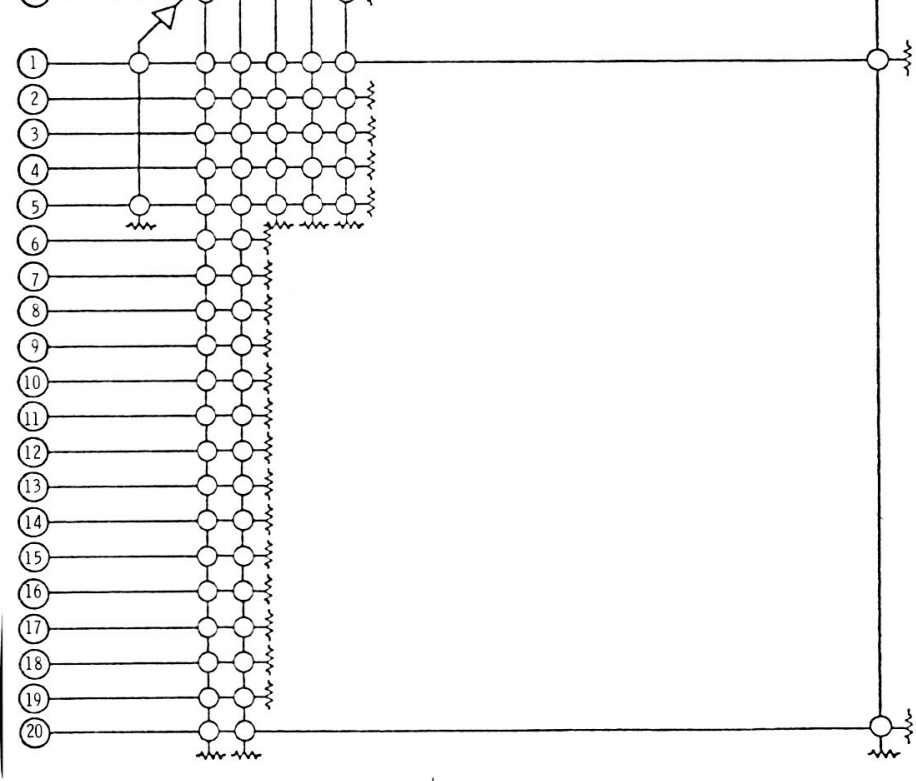

(A) CROSSPOINT DISTRIBUTION.



(B) PHOTOGRAPH.

FIGURE 3. - GE POC MATRIX SWITCH. 


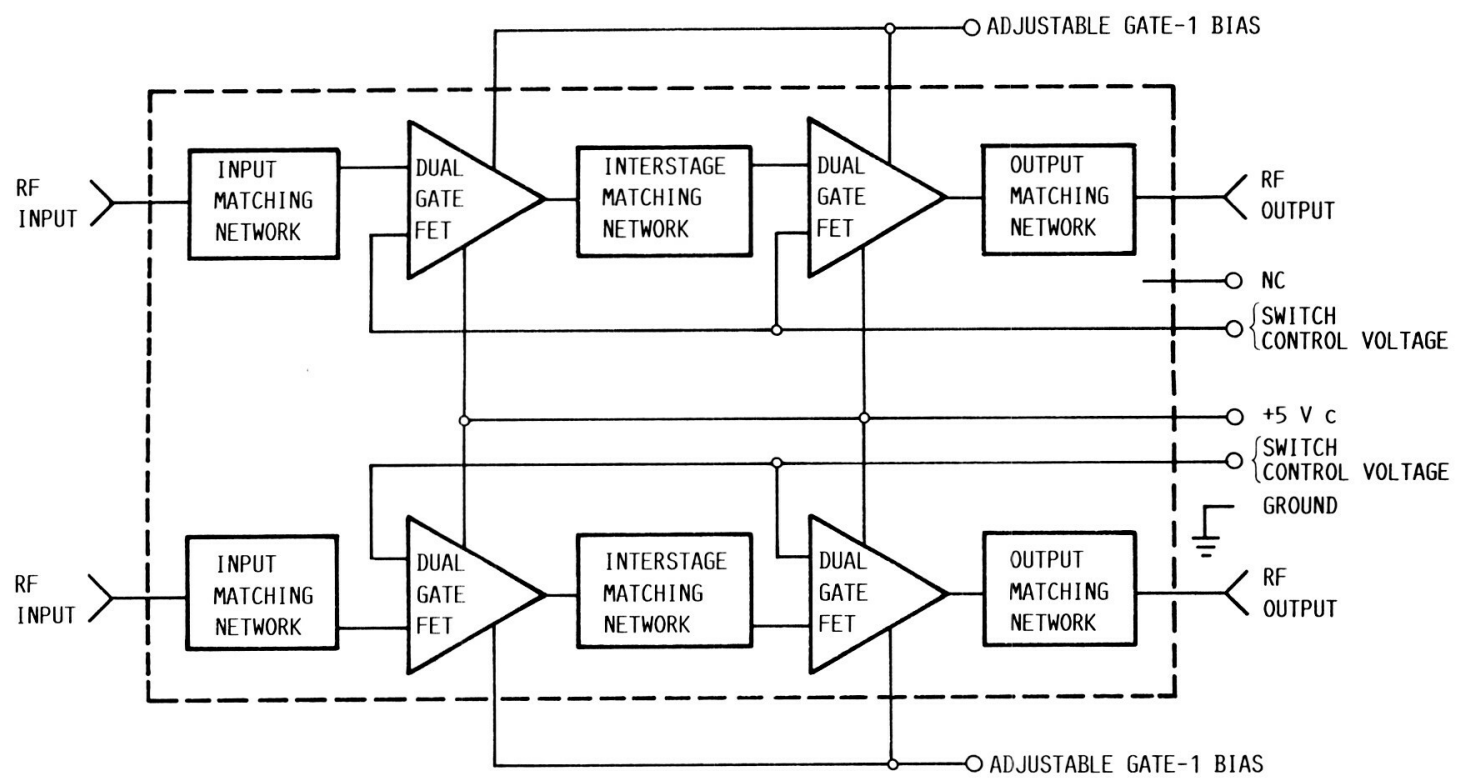

(A) BLOCK DIAGRAM OF FORD SWITCH/AMPLIFIER MODULE.



(B) PHOTOGRAPH OF FORD CROSSPOINT PAIR. FIGURE 4. - THE FORD CROSSPOINT DESIGI. 


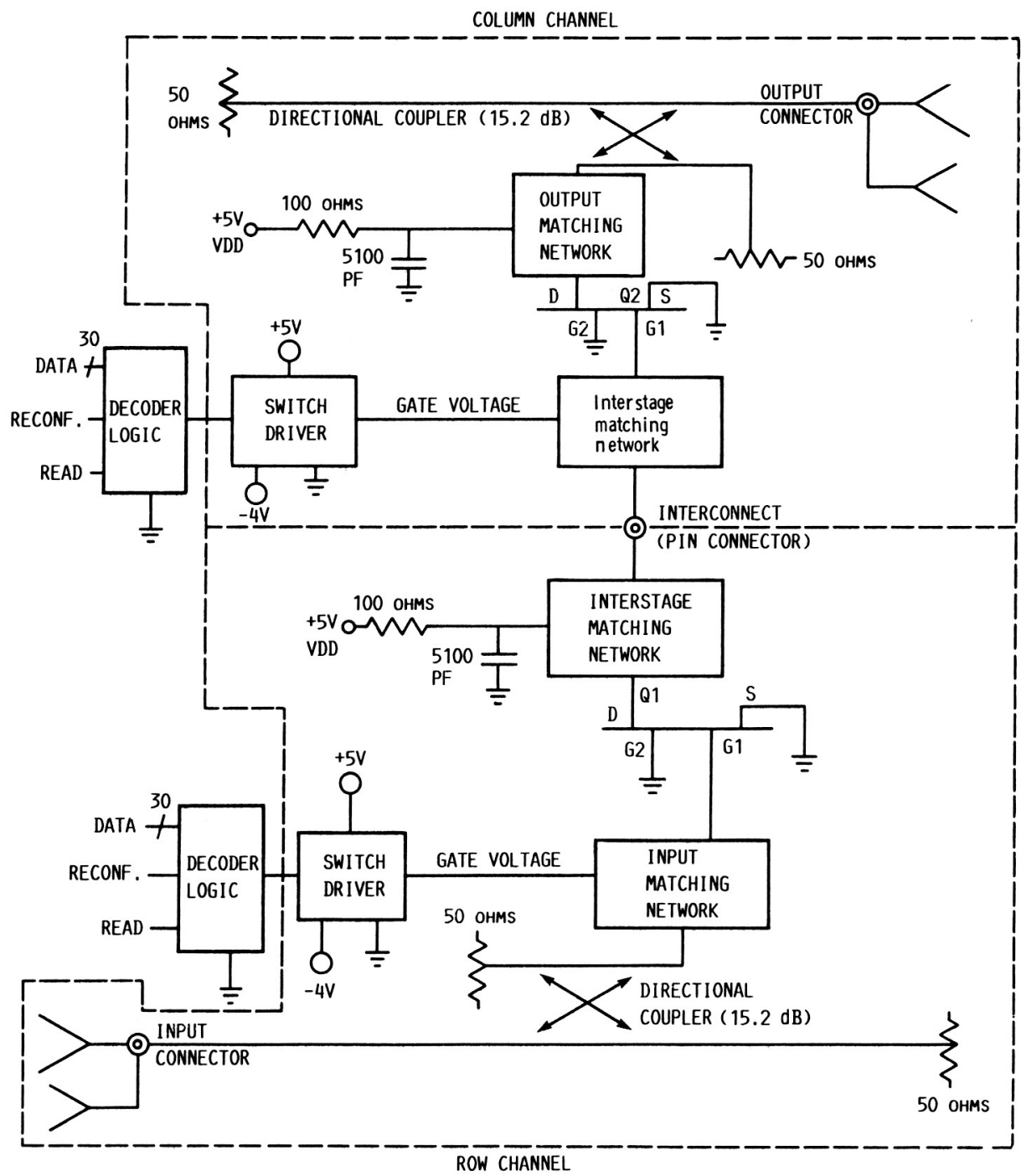

(A) BLOCK DIAGRAM.

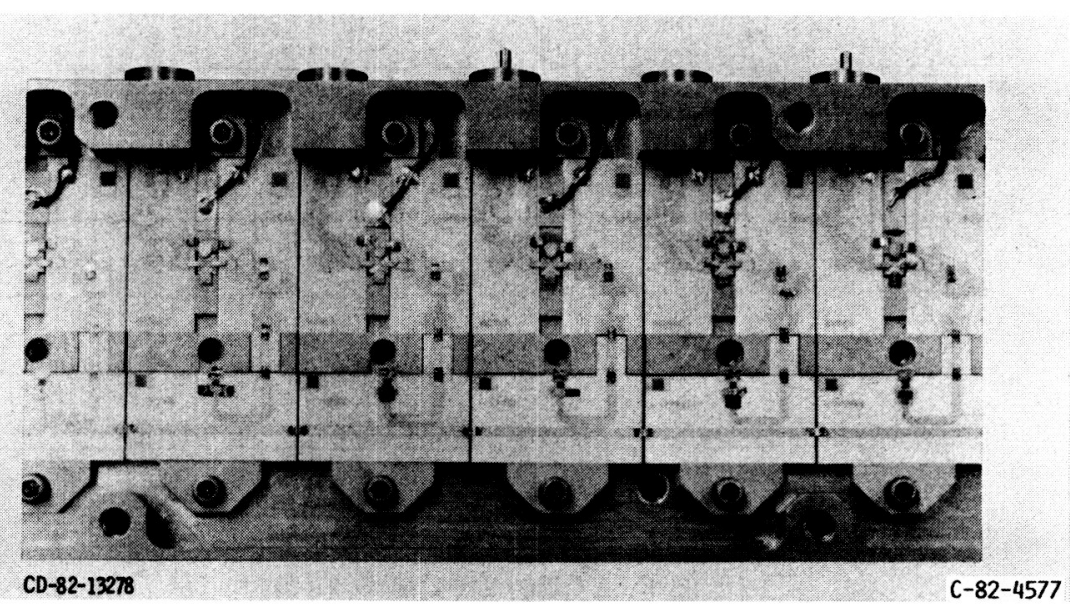

(B) PHOTOGRAPH OF GE CROSSPOINT MODULE. FIGURE 5. - GE CROSSPOINT. 




(A) FORD CROSSPOINT.

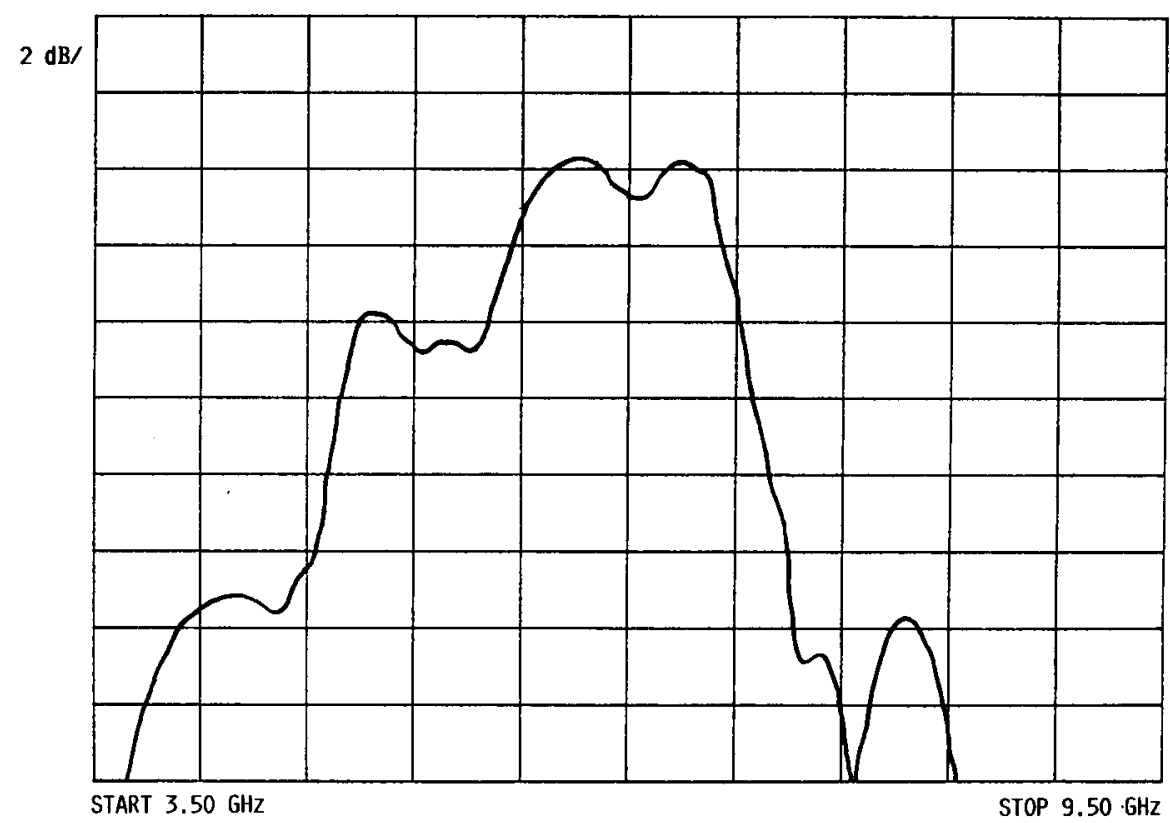

(B) GE CROSSPOINT.

FIGURE 6. - TYPICAL FREQUENCY RESPONSE. 


\section{ORIGINAL PAGE IS \\ OF POOR QUALITY}
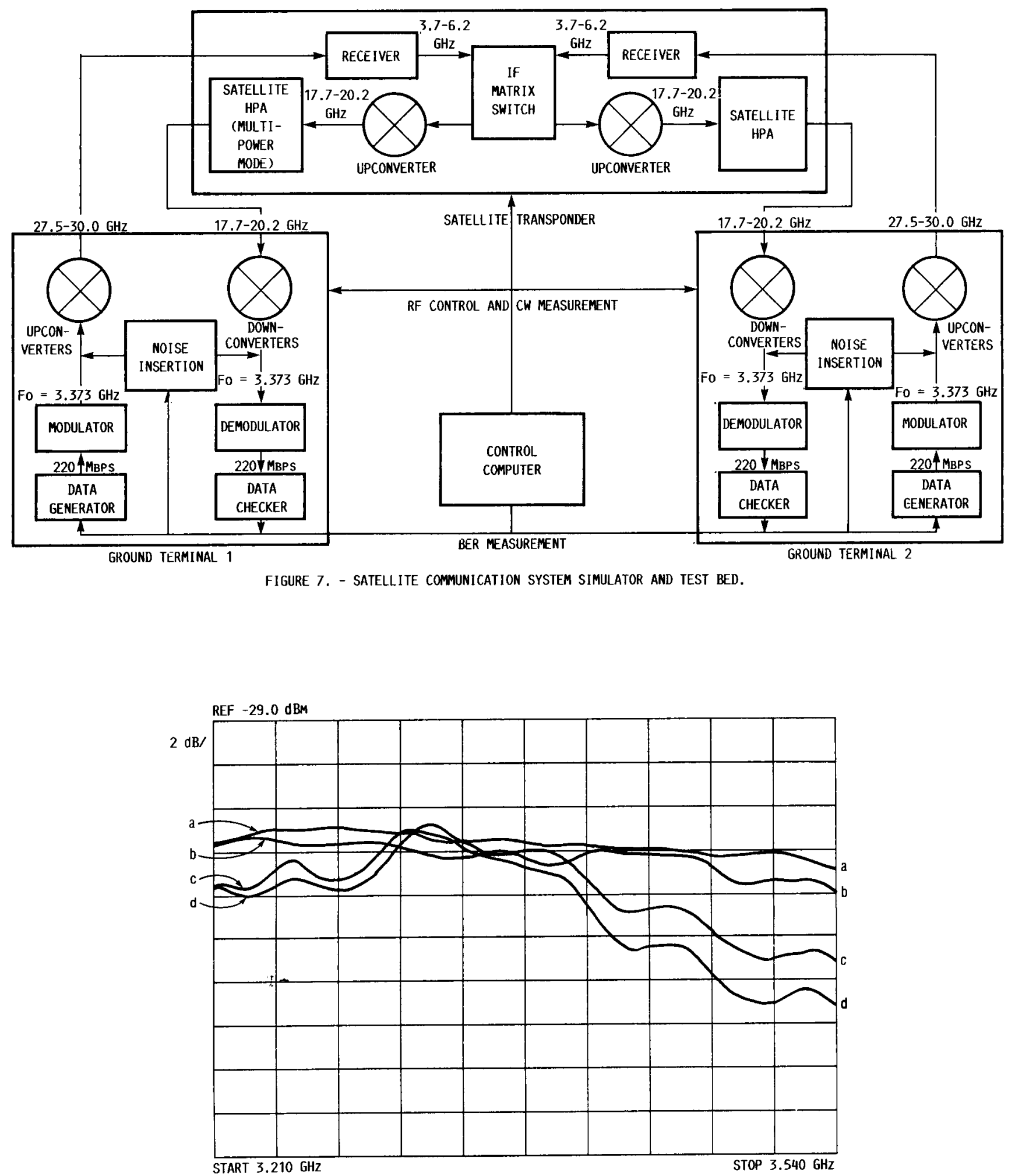

FIGURE 8. - SYSTEM FREQUENCY RESPONSE WITH THE FORD POC MATRIX SWITCH (CROSSPOINT 6-5) IN TEST BAND C. (a) MATRIX SWITCH BYPASSED. HPA SATURATED. (b) HPA SATURATED.

(c) HPA AT $1 \mathrm{~dB}$ COMPRESSION. (d) HPA LINEAR. 




(B) GE CROSSPOINT 5-2.

FIGURE 9. - MEASURED BIT-ERROR RATE CURVES WITH THE HPA AT SATURATION, $1 \mathrm{~dB}$ COMPRESSION, AND LINEAR.

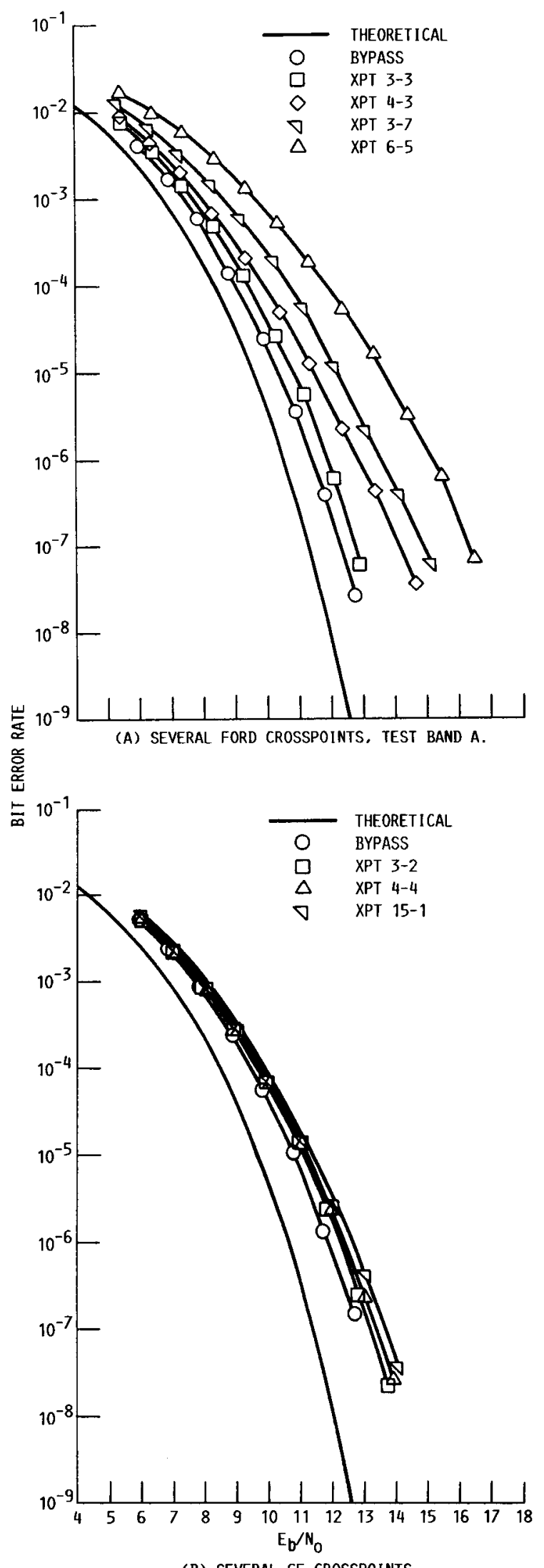

(B) SEVERAL GE CROSSPOINTS.

FIGURE 10. - MEASURED BER CURVES WITH THE HPA AT SATURATION. 


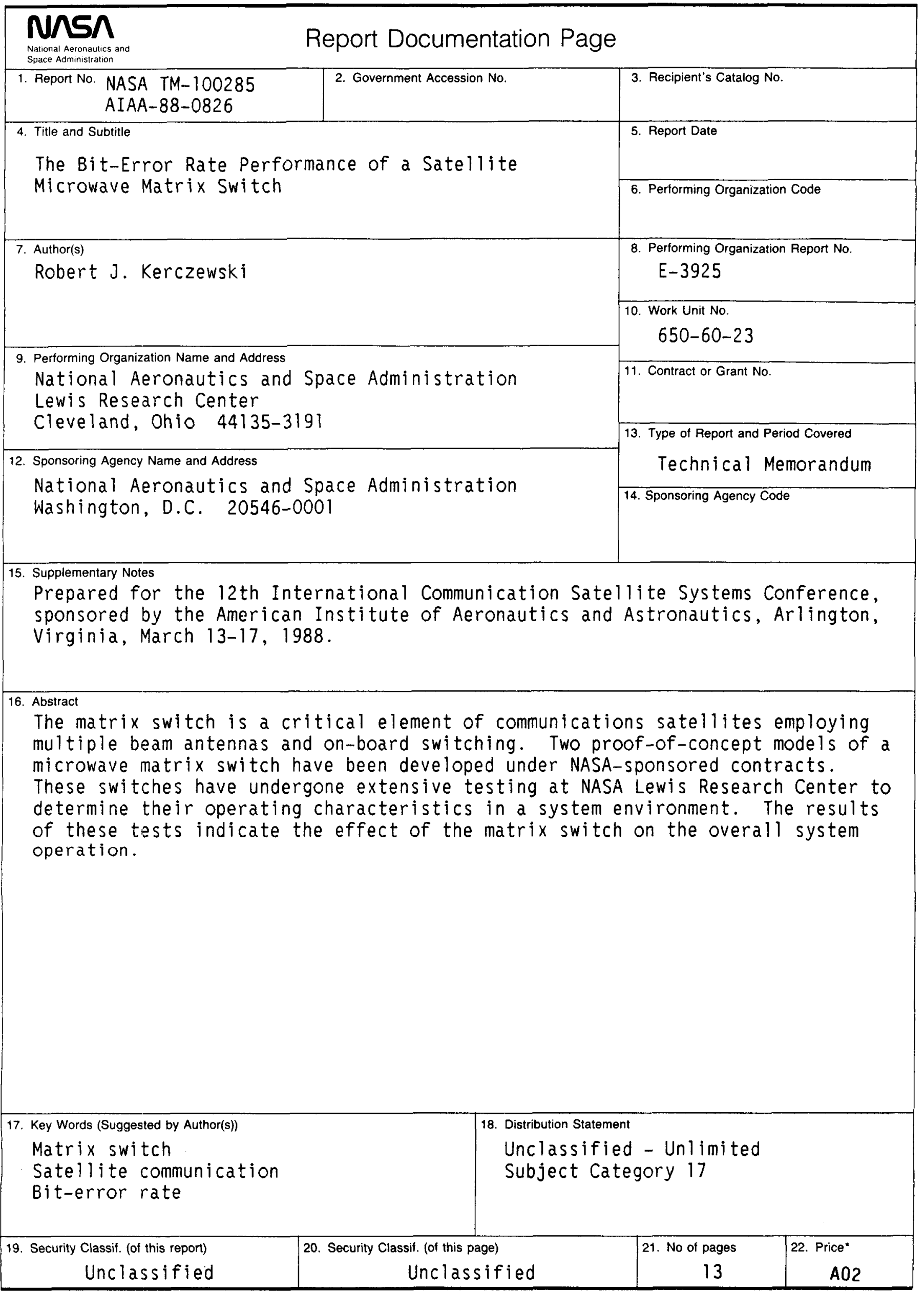

16. Abstract
The matr
multiple
microwave
These sw
determine
of these
operation

ASA TM- 100285

2. Government Accession No

3. Recipient's Catalog No.

5. Report Date

6. Performing Organization Code

8. Performing Organization Report No.

E-3925

Work Unit No.

$650-60-23$

Technical Memorandum

4. Sponsoring Agency Code 